\title{
The impact of digital technology on the quality of higher education
}

\author{
Elena Zaborova \\ Ural State University of Economics, Department of Applied Sociology, 620144 Yekaterinburg, \\ Russia
}

\begin{abstract}
COVID-19 pandemic intensified the transition to online learning practices. The article aims to analyse how students perceive distance education quality compared to face-to-face education mode. The author argues that the groups of social actors, interested in the promotion of distance education in higher schools, include: university leadership, geographically and physically disadvantaged students. In the period 20152020 the group of USUE researchers conducted a series of students' surveys. Analysing the survey findings, the author states that despite the benefits of distance education, students consider that the quality of distance learning is inferior to the traditional face-to-face education mode. Among the problems faced by students in distance learning, is their inability to select information, assess its reliability, and differentiate significant information from insignificant. It is concluded that it is of great importance to continue research into the impacts of digitalization on the quality of higher education.
\end{abstract}

\section{Introduction}

We live in the information era, which means a dramatic increase of the information role in the life of society, its transformation into the major productive force, an essential condition for the progress of society and the functioning of the individual. The information age is also called the digital age, thereby emphasizing the rapid introduction of digital technologies, new technical tools, new software and large databases into our lives. The sphere of education is going through these processes as well, as a result, distance forms of education are spreading rapidly, the role of the Internet as a source of knowledge is growing, and the role of the teacher is changing. For Russia, the field of education is of great importance, Russians have not only access to information, but also to education: currently more than half of Russians $(54 \%)$ aged 25 to 64 years have university degrees (in Canada $-51 \%$, in Israel $-46 \%$, in Japan $-45 \%$, in the UK, Finland, Australia - 38\% respectively) [1]. Thanks to digital technologies, the possibility of intercultural interaction between different countries has increased. How will these new processes affect the quality of education? What are the advantages and disadvantages of digitalizing the educational process in higher school? The search for answers to these questions is very relevant.

Methodologically, the paper is based on conceptual approaches set forth in the works of Russian and foreign researchers. The problem of the information society and its characteristics has been studied by the classics of scientific thought D. Bell, M. Castels, N. Luman, J. Masuda, A. Molya, M. McLuen, W. Rostow and others. The problem of 
education quality in the context of information and digital processes is now attracting the attention of a wide range of scientists. E.D. Zakunova, A.E. Anisimova, E.A. Seregina [2], K.V. Sluzneva, K.S. Gordeev, A.A. Zhidkov consider distance education as one of the methods of obtaining education [3]. The advantages and disadvantages of distance education are considered by A.A. Vlasova, E.A. Porseva [4], E.A. Rybina, V.A. Rotanova, A.I. Toropova [5] and other authors. G.A. Bondareva, N.A. Guz, N.A. Petrova study trends in digitalization of higher education [6].

\section{Materials and methods}

The article is based on empirical data obtained as a result of a number of sociological studies conducted by the authors' team of the Ural State Economic University from 2015 to 2020 $(2015, \mathrm{n}=703 ; 2016, \mathrm{n}=830 ; 2019, \mathrm{n}=571 ; 2020, \mathrm{n}=200)$. The research in 2015-2019 was based on studying the opinions of respondents of the Ural State University of Economics (USUE) and Ural Federal University (UFU), in 2020 the data were collected as a result of the study "Assessment of Education Quality by USUE Students" $(n=200)$, conducted by the USUE Department of Applied Sociology. The author's tools for data collection were developed with the account of empirical experience in sociology.

\section{Results and discussion}

The research results demonstrate the increasing influence of digitalization on all aspects of the educational process, information technologies are penetrating into all elements of the educational system (its organization, planning, the educational process itself). The situation caused by the COVID-19 pandemic has led to either an almost complete transfer of the educational process to a remote form, or a significant increase in its share in the pedagogical process. Distance learning is becoming typical, day-to-day practice. Forced to engage in remote learning and teaching, students and teachers began to actively master new technologies for submitting material, assessing students' knowledge, and communicating online. At the same time, unfortunately, the quality of education has not improved.

Back in 2017, we wrote that distance education is undoubtedly beneficial for a number of social actors [7]. Therefore, it is beneficial primarily to the leadership of universities, since it means significant financial benefits with insignificant material costs. In an environment where most universities rely mainly on their own sources of funding, without any state assistance, distance education helps universities save on the classroom maintenance, educators' trips, and catering facilities. In addition, promoting a distance form of education means acting progressively, in line with the trajectory prescribed by the state, helps to position the university as an advanced educational institution. That is why university administrations actively promote distance education.

The second group supporting this form of study is the students themselves, especially students living in remote areas (those who are initially deprived of the opportunity to study in person due to the limited physical functions also can be referred to this group). As our research has shown, many of them are married people having to jungle work and study commitments. For them, distance learning is an effective way to obtain a diploma in higher education, without breaking away from the family and workplace. If you add to this the fact that distance learning is much cheaper than full-time education, then the result becomes predictable: students support distance learning via the Internet. In 2019, answering the question "If you currently had the opportunity to choose a form of education, then what would you prefer?" our respondents replied that they would choose distance learning (72.9\%) and traditional training $(27.1 \%)$. Here, perhaps, we see the largest difference compared to the 
previous study (2015). Previously, 53.1\% of respondents would choose distance learning and $46.5 \%$ preferred traditional learning.

While supporting distance learning, respondents are clearly aware that the quality of education they receive is lower than in full-time mode of learning. In terms of the quality of knowledge obtained, the remote form cannot compete with the traditional one: $32.4 \%$ of respondents noted that the traditional form provides more opportunities for obtaining quality knowledge. Only $9.2 \%$ of students indicated that the distance form provides more opportunities for obtaining high-quality knowledge. Blended learning was considered effective by $27.6 \%$ of respondents (2019). Data from the latest study (2020), when full-time students were forced to combine full-time and distance learning, showed that $41.2 \%$ of fourth-year students surveyed prefer full-time education (traditional classroom learning) to other learning formats, a third of students $(32 \%)$ advocate blended learning when distance learning technologies replace part of classroom-based classes (for example, theoretical lectures); only $14 \%$ of students preferred distance learning in the format of real-time webinars; and $12.5 \%$ of students would prefer a "full-time distance learning": to listen to recorded lectures at the time convenient for them.

As we can see, the number of those who choose a full-time (classical classroom) form of learning has increased. The number of those who choose a mixed form of training has also risen. The fact that the number of those who prefer the distance form is also higher can be interpreted as a reflection of the fact that remote technologies have firmly integrated into the educational environment and it would undoubtedly be naive to resist their penetration.

Another fact of the educational environment was that the Internet has penetrated into our everyday reality. All experts are unanimous in assessing the positive aspects of the Internet and its enormous role in the development of intercultural cooperation. The Internet has become the main source of information for students. In the recent past, students mainly read books in libraries, listened to lectures by teachers and this educational material was a basic source of information for them. Today they rely on information from the Internet, many books are digitized and posted online, electronic magazines and newspapers are published. However, can the Internet be considered a reliable source of information? As the analysis of the scientific literature shows, it is impossible to rely entirely on this source, rather it is essential to develop criteria and an algorithm to be used for checking information obtained from the Internet.

There is a lot of information on the Internet and it is easily accessible, which can undoubtedly be considered the merit of this information base. However, the source of this information can be anyone, including a not very competent user. Therefore, the question of assessing the information reliability is acute. The abundance of information that today is estimated as an information explosion (in the five previous years, more information was produced by humanity than in the entire previous history, the volume of information in the world increases annually by $30 \%$.), gives rise to another problem - its selection. This, in turn, requires time, perseverance, self-organization skills. As our studies showed, not all students have this set of qualities: among the main difficulties that students face when studying online, they point out "a high degree of independent work" (56.6\%), "the need for self-organization of the learning process" (34.2\%), "lack of constant control by the teacher" (22\%) (2019).

Knowledge is a form of information that is dominated by logic, clarity, rigor, a clear distinction between truth and error, its pinnacle is scientific knowledge. The information itself does not imply in-depth immersion in the subject under study; it is superficial and useful for solving practical problems. Fragmented stimulus patterns [8], chaotic movement of frames, sounds, narratives, etc. are observed in Internet information, elements of reality and fiction are mixed in it. It resembles wisdom, but is devoid of its depth. In the information space, events in their material existence are included in a virtual context filled with simulations. Today, for a person, disaster films do not differ from the disaster itself. The 
result is the spread of semblance outside the television screen or computer display to the real experience of a person, which he is no longer able to distinguish from the virtual reality [9].

It should be stressed that human education also implies a high level of moral development, but there are virtually no filters on the Internet that would block immoral information, cruelty, Internet trolling. As a result, today the path to true education has become longer. S.N. Golubchikov fairly states "From the long pedagogical experience the author drew a conclusion: despite the growing informatization, knowledge of the computer, Internet technologies, students forgot how to think, reflect, and draw conclusions from the material they read. A rare defence of the diploma thesis takes place without the student (master, and a venerable scientist) being able to make a report without reading it on a piece of paper or from the presentation screen... more and more authors cannot express their thought in a clear, understandable, simple language..." [10]. Today, in this situation, the role of a teacher is indispensable; it is increasing, since many students themselves cannot assess the reliability, importance and value of the information that they receive. As our research has shown, students need the advice of teachers and their assistance.

\section{Conclusion}

In 2017, President of the Russian Federation V.V. Putin put forward the thesis that the digital economy will determine the future and act as the locomotive of the country's development. The issue of digital transformation strategy of the Russian economy was put on the agenda [11]. Today it is believed that it is digital transformation that will become the material and technical embodiment of nano - and biotechnology, artificial intelligence, the "Internet of things", robotics and other modern technologies based on electronic devices, this will be the economy of the sixth technology revolution, so the introduction of digital technologies into the educational space seems to be an inevitable process. Without a doubt, the very fact that students and teachers attempt to master Internet technologies is already an indicator of their level of competence, the search and absorption of information through the Internet is one of the options for self-education that is so vital in the current era.

It is essential to study further the impact of digitalization on higher education in general and on the quality of higher education obtained, in particular. While the situation is constantly changing, several aspects of the problem remain unclear. Thus, the position of teachers regarding the introduction of new digital technologies in the gender and gender-age context, an analysis of the effectiveness of using various methods in online teaching (for example, the effectiveness of tests or presentations) require further investigation.

\section{References}

1. V.N. Stegniy, Formation of the Humanitarian Environment at the University, 1, 13 (2017)

2. E.A. Seregina, Perspect Sci Educ, 2, 25 (2018)

3. E.D. Zakunova, A.E. Anisimova, K.V. Sluzneva, K.S. Gordeev, A.A. Zhidkov, Econ Manag Innov Tech, 11, 88168 (2018)

4. E.A. Porseva, Econ Manag Innov Tech, 5, 89328 (2019)

5. E.A. Rybina, A.A. Vlasova, V.A. Rotanova, A.I. Toropova, A.S. Sochneva, Econ Manag Innov Tech, 6, 92561 (2020)

6. N.A. Petrova, G.A. Bondareva, World Sci Cult Educ, 5, 353 (2019)

7. E.N. Zaborova, I.G. Glazkova, T.L. Markova, Sociol Res, 2, 131 (2017)

8. G.V. Osipov, S.V. Klimovitsky, Human Socio-Econ Soc Sci, 5, 54 (2018) 
9. M. Castells, The information age: Economy, society and culture (Wiley-Blackwell, New York, 1999)

10. S.N. Golubchikov, Bul Environ Educ in Russia, 3, 22 (2015)

11. Yu.V. Yakutin, Manag Bus Adm, 4, 27 (2017) 